\title{
Articulação de políticas públicas a partir dos fóruns de competitividade setoriais: a experiência recente da cadeia produtiva têxtil e de confecções*
}

\author{
Samuel A. Antero**
}

S UMÁRIO: 1. Introdução; 2. Fórum de Competitividade: conceito e objetivos; 3. Panorama da cadeia produtiva têxtil e de confecções; 4. Fórum de Competitividade da Cadeia Produtiva Têxtil e de Confecções: resultados e desafios; 5. Conclusões.

Summary: 1. Introduction; 2. Competitiveness Forum: concept and goals; 3. Outlook of the textile and garment production chain; 4. Competitiveness Forum of the Textile and Garment Production Chain: results and challenges; 5. Conclusions.

PALAVRAS-CHAVE: competitividade; cadeia produtiva têxtil e confecções; políticas públicas.

KEY WORDS: competitiveness; garment and textile production chain; public policies.

Este artigo reflete sobre a ação do Fórum de Competitividade da Cadeia Produtiva Têxtil e de Confecções como articulador de políticas públicas e apresenta sugestões/ alternativas para essa cadeia produtiva. Inicia com um panorama sobre o fórum de competitividade, demonstrando seu conceito, objetivos e metodologia de trabalho, que prevê o consenso tripartite (empresários, trabalhadores e governo) para a formulação de políticas públicas. Em seguida, desenvolve uma análise da evolução recente da cadeia produtiva têxtil e de confecções, buscando produzir um primeiro balanço dos problemas e potencialidades identificados. O artigo também analisa a experiência

\footnotetext{
* Artigo recebido em mar. e aceito em nov. 2005.

** Coordenador do Curso de Formação para Especialistas em Políticas Públicas e Gestão Governamental e Analistas em Ciência e Tecnologia. Graduado em administração de empresas pela Universidade Estadual do Ceará, especialista em políticas públicas e gestão governamental pela Escola Nacional de Administração Pública (Enap). Endereço: SQSW 302, bloco E, ap. 606 - CEP 70673-205, Brasília, DF, Brasil. E-mail: samuelantero@hotmail.com.
} 
desse fórum de competitividade setorial, visando identificar inovações e problemas na coordenação e cooperação dos diversos atores para a consecução de políticas setoriais de desenvolvimento. Por último, aborda os principais desafios e dificuldades, dando especial ênfase a duas questões estratégicas: as ações para geração de emprego e renda e as ações para o desenvolvimento da competitividade da cadeia têxtil e de confecções.

Sectorial competitiveness forums and public policy articulation: the recent experience of the textile and garment production chain

This article reflects upon the role of the Competitiveness Forum of the Textile and Garment Production Chain in public policymaking, and presents suggestions/alternatives for this chain. It begins by presenting an overview of the competitiveness forum, outlining the concept, objectives and work methodology, which calls for a tripartite consensus (business, workers, and government) in public policymaking. In then examines the recent evolution of the textile and garment production chain, so as to present a balance of the identified problems and potentials. It analyzes the experience of this sectorial competitiveness forum so as to identify innovations and issues regarding the coordination and cooperation of the several agents involved in sectorial development policy-making. Finally, the article presents the main challenges and difficulties, focusing on two strategic issues: employment and income generation measures, and competitiveness development actions for the textile and garment production chain.

\section{Introdução}

As cadeias produtivas, segundo Prochnik e Haguenauer, citados por Cetiqt (2003), provêm, por um lado, do crescente processo de desintegração vertical e da divisão do trabalho e, por outro, da maior interdependência, originada por pressões competitivas entre os agentes econômicos. Cadeia produtiva pode ser então definida como o conjunto de etapas consecutivas pelas quais passam e vão sendo transformados e transferidos os diversos insumos. Cadeias produtivas setoriais são aquelas em que as etapas são setores econômicos e os intervalos são mercados entre setores consecutivos.

Assim conceituada, a cadeia produtiva têxtil e de confecções (CTC) inicia-se, de maneira simplificada, na agropecuária (fibras naturais) ou na indústria química (fibras manufaturadas), passando pelo fio, tecido, beneficiamento, confecção e termina no consumidor final. Dada a característica de extrema heterogenia no que diz respeito às matérias-primas utilizadas, processos produtivos existentes, padrões de concorrência e estratégias empresariais, torna-se uma cadeia de difícil formulação e implementação de políticas públicas. 
Na década de 1990, a CTC foi uma das que mais sentiu o impacto da abertura comercial e da sobrevalorização cambial verificada no período pós-Plano Real. Para fazer face ao desafio lançado pelo incremento da concorrência causado pelas importações, todos os elos foram forçados a se ajustar, o que não foi realizado de forma homogênea, mas, de imediato, gerou impacto positivo em termos de competitividade.

Todas as reestruturações verificadas em termos de aparato tecnológico, gestão de pessoas e custos, e estratégias empresariais foram vitais para a sobrevivência da cadeia sob o novo contexto de competição. Hoje a CTC representa 1\% do PIB brasileiro (valor adicionado), gera cerca de 13,9\% dos empregos industriais, e fatura cerca de US\$ 22 bilhões.

Cabe destacar, no entanto, que alguns elos, apesar de terem um grau de competitividade superior ao observado no início desse processo, ainda não se encontram no nível de competitividade dos principais concorrentes do mercado mundial, necessitando de outro esforço que não só o de se ajustar. Trata-se de se dar outro salto competitivo para que o país se torne novamente um player significativo no mercado mundial.

Nesse contexto, foi constituído, em 30 de maio de 2000, o Fórum de Competitividade da Cadeia Produtiva Têxtil e de Confecções, um espaço tripartite de construção de políticas entre governo, empresários e trabalhadores em busca não somente de identificar gargalos, oportunidades e desafios da cadeia, mas definir, também, uma agenda de metas e ações desafiadoras de sua capacidade competitiva, conforme a estratégia de um "diálogo para o desenvolvimento".

Este artigo discorre sobre a evolução recente dessa cadeia, analisar a ação do Fórum de Competitividade da Cadeia Produtiva Têxtil e de Confecções como articulador de políticas públicas e apresentar sugestões/alternativas de políticas públicas para essa cadeia produtiva.

Com a finalidade de dar um panorama mais amplo sobre o Fórum de Competitividade (que compõe o Programa Brasil Classe Mundial, integrante dos Planos Plurianuais 2000-03 e 2004-07), a próxima seção demonstrará seu funcionamento geral e metodologia de trabalho, que prevê o consenso tripartite para a formulação de políticas públicas.

A seção seguinte analisará a configuração da CTC brasileira, para identificar os principais elos, atores envolvidos e padrões de desenvolvimento de cada elo. Buscará também resgatar, brevemente, a evolução recente (na década de 1990) da CTC no Brasil e descrever algumas das políticas que afetaram o desempenho da cadeia no período. Almeja-se, com isso, produzir um primeiro balanço dos problemas e potencialidades identificados.

A seguir, será desenvolvida uma análise específica da experiência do Fórum de Competitividade da CTC, com o intuito de identificar inovações e problemas na 
coordenação e cooperação dos diversos atores para a consecução de políticas de desenvolvimento para essa cadeia produtiva.

Seguem-se, por fim, notas conclusivas em que se desenvolverá uma análise do que já foi alcançado e do que se almeja realizar entre as propostas apresentadas pelo Fórum de Competitividade, dando especial ênfase a duas questões estratégicas: as ações para geração de emprego e renda e para o desenvolvimento da competitividade da cadeia têxtil e de confecções.

\section{Fórum de Competitividade: conceito e objetivos}

O Fórum de Competitividade compõe o Brasil Classe Mundial, programa integrante dos Planos Plurianuais 2000-03 e 2004-07, sob a coordenação do Ministério do Desenvolvimento, Indústria e Comércio Exterior (MDIC), e com o gerenciamento da Secretaria do Desenvolvimento da Produção (SDP).

O fórum constitui-se de

espaços de diálogo entre empresários, trabalhadores e governo para, em primeiro lugar, promover a discussão e a busca de consenso em relação aos gargalos, oportunidades e desafios de cada uma das cadeias produtivas que se entrelaçam na economia brasileira. Após o consenso em torno de um diagnóstico, os debates são dirigidos para a definição de um conjunto de ações e metas desafiadoras para a solução dos problemas e aproveitamento das oportunidades, tendo em vista os objetivos do programa (geração de emprego, ocupação e renda, desenvolvimento produtivo regional, capacitação tecnológica, aumento das exportações, competição com as importações, e competição com serviços internacionais).

(MDIC, 2000)

Em um contexto em que a política moderna aceita que o Estado não é o ator dominante no processo político e reconhece a variedade de atores não-governamentais que participam do cenário público e dos processos de tomada de decisões (Zurbriggen, 2003), a noção de política industrial (Política Industrial, de Comércio e Serviços) proposta pelo Fórum de Competitividade é essencialmente inovadora na medida em que aumenta a capacidade de diálogo entre os empresários, trabalhadores e governo, criando uma rede de políticas, ou policy network, ${ }^{1}$ que permite

\footnotetext{
${ }^{1}$ Mais especificamente, no modelo de redes de Marsh e Rodes, apresentado por Zurbriggen (2003), poder-se-ia enquadrá-lo como uma rede fechada (comunidade política), em que a integração se dá por consenso e, portanto, com certo grau de acordo (conflito presente).
} 
uma melhor organização da demanda do setor produtivo e sua priorização de atendimento pelo governo.

As metas e ações, por sua vez, têm que ser entendidas como desafiadoras e exeqüíveis em relação a cada um dos fatores que estão relacionados com gargalos e oportunidades na cadeia produtiva (sempre tendo como parâmetro a correspondente cadeia internacional concorrente), devendo ser priorizadas a partir de elementos dinâmicos da cadeia, de forma a aumentar seu impacto e resultar em incremento de competitividade para as empresas, produtos e serviços da cadeia produtiva.

Para a seleção e priorização das cadeias produtivas foram consideradas as potencialidades de cada cadeia em termos de ganhos de competitividade (expressos pelos objetivos específicos: aumento das exportações e competição com as importações); aumento do nível de emprego, ocupação e renda (expresso pelo objetivo específico de geração de emprego); e desconcentração produtiva (expresso pelo objetivo específico de desenvolvimento regional).

Ressalte-se que os fóruns de competitividade se coadunam com as diretrizes de política industrial, tecnológica e de comércio exterior do novo governo. De fato, há uma área de interseção entre o fórum e as novas diretrizes, principalmente no que tange à preocupação com o aumento da eficiência econômica e do desenvolvimento e a maior inserção do país no comércio internacional (Brasil, 2003). Assim, os fóruns seriam instrumentos ou redes nas quais as políticas setoriais seriam maturadas, com vistas a emitir recomendações sólidas no processo de se formular políticas, administrar adequadamente os processos envolvidos e alcançar os resultados desejados.

Até o final de 2003, as seguintes cadeias produtivas foram objeto de fóruns de competitividade: construção civil, têxtil e confecções, couro e calçados, plástico, complexo eletrônico, madeira e móveis, transporte aéreo, turismo, automotivo, indústria aeroespacial, siderurgia, farmacêutica, bens de capital, higiene pessoal, perfumaria e cosméticos e indústria agroquímica.

A seguir, dar-se-á enfoque na cadeia produtiva têxtil e confecções, objeto do trabalho. Primeiramente segue uma apresentação da cadeia, com um breve relato de seu desenvolvimento recente e posteriormente será discutida a experiência específica deste Fórum de Competitividade setorial.

\section{Panorama da cadeia produtiva têxtil e de confecções}

Nos próximos anos, o Brasil enfrentará alguns desafios críticos para a sustentação do seu desenvolvimento econômico. Entre eles, deve-se destacar a reestruturação de sua inserção internacional. Por conseguinte, um objetivo prioritário a ser perseguido pela 
gestão da política econômica deveria ser o aumento de competitividade do setor produtivo, contribuindo para que o Brasil reestruture sua pauta exportadora e ocupe melhores espaços na economia internacional (Coutinho, Hiratuka e Sabbatini, 2003).

A evolução do processo de integração entre as economias nacionais e a importância cada vez maior das novas tecnologias nas atividades econômicas têm acirrado a competição nos mercados interno e externo, impondo a necessidade de competitividade das cadeias produtivas, em padrões internacionais, como vetor do desenvolvimento econômico do Brasil nos próximos anos.

A elevação da competitividade das cadeias produtivas é um propósito complexo, que envolve políticas de natureza sistêmica, em boa medida dependentes de iniciativas do governo, de natureza estrutural, de âmbito setorial, e ações de domínio empresarial relativas aos fatores microeconômicos. Portanto, é um objetivo que deve ser construído de forma integrada por todos os atores envolvidos e torna-se imperativo que as estratégias e aspectos da competitividade sejam ordenados de maneira sistêmica ao longo da cadeia, de forma que os impactos sejam positivos para todos os elos, ainda que algum elo possa estar fora do Brasil.

Para uma melhor visualização da cadeia produtiva têxtil e de confecções, a figura a seguir caracteriza-a de forma ampla.

O final da cadeia é composto pelo elo de confecção, caracterizado por uma grande heterogeneidade dos ramos e elevado grau de atomicidade das firmas, particularmente aquelas nos ramos do vestuário. Uma vez que se trata do elo que agrega mais valor, este deve ser o foco principal das ações na cadeia. No entanto, sua competitividade está comprometida por todos os elos anteriores.

De forma sistêmica, segue uma breve descrição de como os principais elos enfrentaram o desafio da concorrência internacional e de que forma suas estratégias geraram impactos nos elos seguintes. 


\section{Configuração básica da cadeia produtiva têxtil e de confecções}

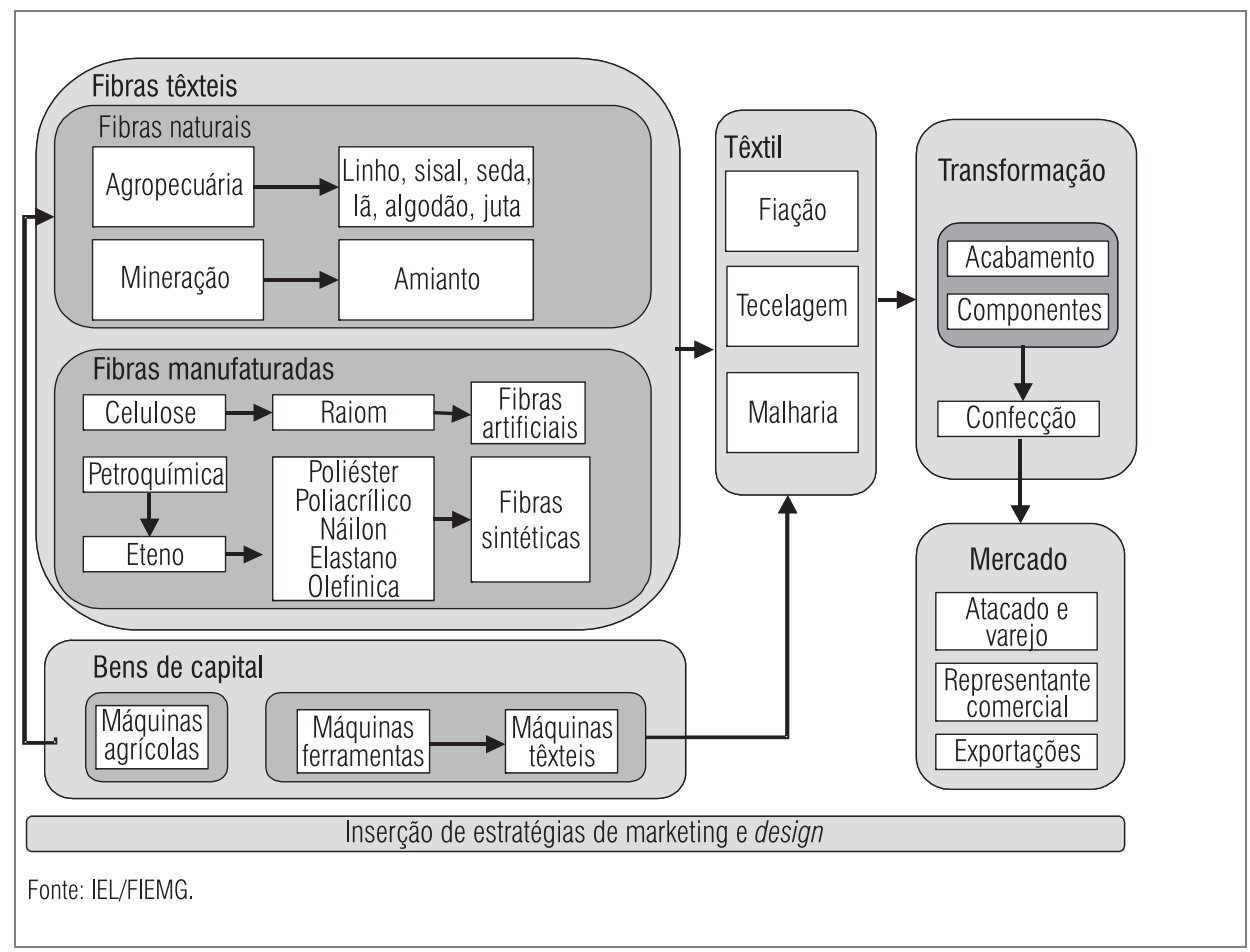

\section{Algodão}

Principal matéria-prima utilizada pela cadeia têxtil nacional, o algodão brasileiro é, talvez, o elo que mais explicitamente tenha mostrado resultados em termos de competitividade nos últimos anos.

O Brasil ocupava o terceiro lugar no ranking dos maiores exportadores de algodão do mundo até a década de 1970, quando o foco da política pública prioritária deslocou-se para a indústria têxtil.

Na década de 1980, ainda ocupava posição de destaque. No final dessa década, no entanto, a cotonicultura brasileira teve sua rentabilidade comprometida devido à praga do bicudo, bem como pelo processo de abertura de mercado para o produto. A partir de 1992/93, a política de rebaixamento das alíquotas de importação a zero aliada à combinação de câmbio sobrevalorizado e elevadas taxas de ju- 
ros internas fez as exportações caírem a níveis próximos de zero e a produção decrescer drasticamente.

O consumo de fibra não acompanhou a queda da oferta interna e manteve seu nível médio, passando a indústria a abastecer-se do produto importado mais barato e favorecido por linhas de financiamento a longo prazo e juros mais baixos, além de subsidiado na origem. O algodão nacional perdeu market share e acabou sendo substituído pelo produto importado, deslocando o país, em duas décadas, da condição de um dos maiores exportadores para o primeiro importador mundial em 1996/97 (IEL, 2000).

A necessidade de competir para oferecer à indústria nacional uma fibra comparável com a fibra importada fez o cotonicultor procurar novas fronteiras onde pudesse expandir seus plantios, ocasionando a migração e o início da produção de algodão no Centro-Oeste, principalmente no Mato Grosso (que possui boas condições climáticas e topografia sem similar).

Aliado a isso, crescentes investimentos em pesquisa, tecnologia, análises de custos e prospecção de mercados revolucionaram a produção, não somente em termos quantitativos como qualitativos.

As indústrias de fiação e tecelagem, que operam com equipamento de última geração, são bastante sensíveis à qualidade intrínseca da fibra, e, por isso, vêm acompanhando de perto o salto de competitividade da cotonicultura nacional. Ademais, a concorrência internacional da fiação e tecelagem requer constante atualização do equipamento e o desempenho das máquinas tornou-se indispensável para assegurar a competitividade do produto.

\section{Fibras manufaturadas}

As fibras manufaturadas ou químicas, subdivididas em artificiais e sintéticas, surgiram como uma nova opção de matéria-prima a ser utilizada pela indústria têxtil, seja pelo fato de os confeccionados exigirem maior rapidez e menor custo, seja para diminuir a dependência da indústria de eventuais crises de escassez de fibras naturais.

A mistura de fibras manufaturadas e naturais tem adicionado às fibras aspectos como melhor resistência, durabilidade, facilidade de tratamento e apresentação. Muito embora no Brasil o percentual de consumo de fibras naturais ultrapasse o de fibras manufaturadas (estimado em 65\% e 35\%, respectivamente), em termos mundiais há uma tendência de queda na utilização das naturais (cerca de 40\%) e um aumento das manufaturadas (cerca de 60\%), devido a sua maior competitividade relativa.

A competitividade desse elo compromete os elos a jusante, uma vez que, na cadeia têxtil e de confecções, as demandas são provenientes principalmente das 
grandes empresas de tecidos, confecção e comercialização. Os produtos compostos majoritariamente de fibras químicas são a lingerie, moda esportiva e moda praia. Como a demanda dessas aplicações é baixa, os principais clientes dos produtores de fibras manufaturadas incluem grandes processadores de fibras naturais (que utilizam a mistura).

Esse elo é intensivo em capital e matéria-prima, exigindo das empresas investimentos freqüentes em pesquisa e modernização para competir internacionalmente. Durante a década de 1990, as empresas brasileiras de fibras manufaturadas investiram intensamente na ampliação da capacidade produtiva e, após a abertura comercial ocorrida em 1990, a produção de fibras químicas (artificiais e sintéticas) não se reduziu de maneira acentuada, o que indica a competitividade desse elo.

O problema que o país enfrenta é que a produção nacional tem se mantido estável nos últimos anos, enquanto a produção mundial duplicou. Em outros países, há empresas que, sozinhas, produzem quantidade maior que a brasileira, além de terem todas as etapas da produção de fibras e filamentos verticalizadas em uma única empresa. Cabe ressaltar que em termos mundiais está havendo uma mudança na estrutura de produção de fibras químicas. Por um lado, nos EUA e na Europa há uma grande incidência de fusões e incorporações, gerando uma concentração no segmento, por outro, os investimentos desse elo estão se concentrando principalmente nos países asiáticos e a competitividade está se baseando, cada vez mais, em escala de produção. Observa-se, também, que a produção das subsidiárias brasileiras comparada ao total global da produção das maiores empresas é pequena, fato que torna evidente que o país não tem alta prioridade na estratégia global dessas empresas (Fundação Vanzolini, 2001).

\section{Fiação}

O processo de abertura comercial, no início da década de 1990, marcou de forma significativa o elo de fiação, impulsionando-o a enormes alterações estruturais. As empresas que eram protegidas da concorrência externa passaram a concorrer com os produtos provenientes da Ásia e do Mercosul (a participação dos produtos oriundos do Mercosul na pauta das importações brasileiras de produtos têxteis é mais significativa, quando comparada à participação dos têxteis asiáticos).

Segundo dados do Instituto de Estudos e Marketing Industrial (Iemi), ao mesmo tempo que o número de fábricas se reduziu a um terço, gerando forte queda na oferta de empregos, a produção nacional não apresentou redução de maneira considerável, podendo-se afirmar que o elo conseguiu ser competitivo após a abertura. Com isso a produção média por fábrica e por operário chegou a crescer $230 \%$ entre 1990 e 1999. 
Ressalte-se, também, que o elo de fiação é caracterizado mundialmente por um processo de concentração. No Brasil, a maior parte das empresas é integrada e esse processo foi utilizado como estratégia empresarial capaz de sustentar sua competitividade. As mais comuns são fiação-tecelagem, observando-se, também, a integração fiação-tecelagem-acabamento.

No que diz respeito aos produtos, antes da abertura comercial os fios do tipo commodities possuíam um peso extremamente grande nas linhas de produtos das empresas. Com o processo de abertura, passou-se a privilegiar a produção de fios com composições, tipos e variedades diferenciadas, especialmente nas empresas verticalizadas (fiação-tecelagem) que, para produzirem um tecido diferenciado, tinham de partir de fios com certos tipos de especificidade. Atualmente, as empresas têm de se adequar ao produto que o consumidor queira comprar, não o que elas queiram vender, sempre existindo um tipo de "tecido do momento" que exige tipos especiais de fios provenientes de combinações de fibras. Saliente-se, aqui, a importância do salto competitivo dos elos a montante: a melhora da fibra repercute na produção de um fio de qualidade. Ademais, matérias-primas nacionais competitivas significam menores custos indiretos, sem mencionar que algumas empresas de menor porte poderiam ser também beneficiadas por ter dificuldades em conseguir carta de crédito no exterior para importação.

Cabe, por fim, ressaltar a importância do processo migratório de diversas empresas de fiação para o Nordeste. Favorecidas por incentivos e linhas de crédito especiais, as empresas de produção de fios montaram novas e moderníssimas instalações, com equipamentos, processos e tecnologias tão modernas quanto as mais avançadas do mundo.

\section{Tecelagem}

De maneira geral, as mesmas mudanças estruturais observadas na fiação ocorreram nas tecelagens. Após a abertura comercial do início dos anos 1990, esse elo experimentou profundas reestruturações tanto em termos de aparato tecnológico, quanto de estratégias das empresas para poderem sobreviver sob o novo paradigma competitivo instituído.

Nesse contexto, as empresas do setor tomaram movimentos em duas direções distintas: as grandes empresas integradas focaram seus negócios em produtos padronizados, ou seja, commodities. Nestas, grandes investimentos foram realizados em termos de aquisição de maquinário, instalação de modernas unidades, fusões e aquisições entre empresas e utilização de modernas técnicas de gestão com o intuito de racionalizar custos para se tornarem competitivas. Nas empresas não-integradas, a chave para a 
sobrevivência foi a contínua diferenciação de seus produtos, procurando fugir de forma inequívoca dos mercados de commodities. Estas, impossibilitadas em sua maioria de adquirir as novas máquinas, concentraram suas ações na procura contínua de redução de custos, racionalizando a utilização de mão-de-obra, focando sua atuação nos produtos que gerassem maior rentabilidade, fechando fábricas ineficientes e custosas e procurando ao máximo atuar de forma flexível (IEL, 2000).

Segundo o Iemi, houve uma redução de $70 \%$ no número de fábricas, ao mesmo tempo que a oferta de empregos se reduziu em $76 \%$, mas sem perdas na produção nacional. A produção por fábrica cresceu 253\% na década de 1990 e a produção por homem/ano, nada menos que 333\%.

Assim como as fiações, as tecelagens também foram atraídas por vantagens fiscais, principalmente para o Nordeste. Não obstante, a escala da migração foi bem menor, já que, para estas, é fundamental permanecer o mais próximo possível dos confeccionistas, ainda fortemente concentrados nas regiões Sudeste e Sul.

\section{Malharia}

Com a abertura da economia brasileira iniciada em 1990, a participação das importações na disponibilidade interna de tecidos de malha cresceu consideravelmente, uma vez que tínhamos no período 1990-94 uma participação irrisória de 0,13\% em média, passando para cerca de $7 \%$ em 1997 . No tocante às exportações, constata-se que elas nunca foram representativas com relação à produção de malhas, visto que sua participação na produção nacional oscila entre $0,2 \%$ e $0,8 \%$.

A respeito da produção, segundo dados do Iemi, de maneira geral, no período de 1990 a 1999, o número de fábricas se reduziu em 18\%, a mão-de-obra utilizada caiu $25 \%$ e a produção aumentou em $26 \%$. Assim, com produção crescente, queda do número de indústrias e empregados, percebe-se claro aumento da produtividade do segmento, o que acabou acarretando uma melhora da competitividade média do setor. Some-se a isso a crescente importação de máquinas modernas e mais produtivas que também fez com que a produtividade crescesse no segmento. (Dados do IEL apontam que a importação de máquinas para esse segmento passou de uma média de US\$ 54,8 milhões no período 1990-92 para US\$109,7 milhões entre 1994-96.)

Dois fatores ajudam a entender o porquê deste ajuste menos penoso: o fato de ser um segmento com menor dificuldade para a modernização tecnológica e para a entrada de novas firmas vis-à-vis o elo de tecelagem, devido ao baixo volume de re- 
cursos necessários para se implantar uma malharia moderna (cerca da metade do volume necessário para investir em uma tecelagem) e a ocorrência de maior grau de integração da indústria de malharia, principalmente a integração com a confecção (elo que experimentou crescimento constante no número de peças ao longo dos anos 1990). Entretanto, deve-se ressaltar que o acesso mais fácil de empresas a esse segmento trouxe maior grau de informalidade na indústria, fato nocivo à competitividade do segmento no Brasil, em virtude das distorções de preços que as informais inserem no mercado.

Cabe salientar, por fim, que, na malharia produtora de commodities, destaca-se a produção de malhas com $100 \%$ de algodão e a produção de uma malha que mescla algodão com poliéster para a fabricação de camisetas com custo baixo até em relação ao obtido pelos chineses (caso da Coteminas).

\section{Confecção}

Para se analisar a competitividade do elo de confecção no Brasil, deve-se considerar as três características marcantes: de toda a cadeia produtiva, confecção é o elo mais intensivo em mão-de-obra, com grande variedade de produtos e processos produtivos e formado, em sua maioria, por empresas de pequeno porte, muitas na informalidade. Isso impacta negativamente a competitividade da cadeia, pois, distorce o sistema de preços de forma a afetar diretamente a rentabilidade das empresas formais, justamente as que possuem maior capacidade de investimento em modernização.

A intensidade de mão-de-obra faz que esse elo tenha o menor gasto de capital por posto de trabalho entre todos os elos da cadeia produtiva, o que o torna um dos grandes empregadores em qualquer parque industrial do mundo. Além da importância como gerador de empregos, o elo de confecção é aquele de maior contato com as preferências dos consumidores em relação a tipos de tecido, padrões de corte e de cores, sendo, portanto, responsável direto pela comunicação de alterações nos padrões de consumo para os outros elos da cadeia.

A grande heterogeneidade dos produtos, bem como a grande influência da moda, faz com que nem todos os mercados possibilitem a atuação de empresas de grande porte, seja devido à geração de nichos específicos, seja pela flexibilidade produtiva demandada, que só são viáveis economicamente para empresas pequenas.

Segundo estudo do IEL (2000), à parte do segmento de cama, mesa e banho, no qual a indústria nacional possui claramente competitividade internacional, 
percebe-se, após analisar o segmento confeccionista brasileiro, que poucas empresas são atualizadas tecnológica e organizacionalmente (dotadas, entre outras coisas, de bons esquemas de comercialização de sua produção), sendo que a maioria é composta por empresas defasadas que competem no mercado via custo da mão-de-obra ou via terceirização.

\title{
4. Fórum de Competitividade da Cadeia Produtiva Têxtil e de Confecções: resultados e desafios
}

Como destacado por Coutinho, Hiratuka e Sabbatini (2003),

\begin{abstract}
a abertura comercial promovida em contexto de sobrevalorização cambial e desprovida de políticas industriais e tecnológicas não foi capaz de alterar de forma significativa o padrão de especialização das exportações brasileiras. Mas alterou a estrutura produtiva brasileira, que se tornou mais concentrada em setores de menor intensidade tecnológica e mais dependente de insumos importados.
\end{abstract}

No caso específico da CTC brasileira, apesar da modernização e do aumento da produtividade nos anos 1990, o país não conseguiu reverter a tendência de queda de participação no comércio internacional. Como pode ser visto nas tabelas 1 e 2, a seguir (Prochnik, 2002).

Tabela 1

Distribuição do comércio mundial de têxteis, 1995-2000

\begin{tabular}{lcccccc}
\hline Discriminação & 1995 & 1996 & 1997 & 1998 & 1999 & 2000 \\
\hline & & \multicolumn{7}{c}{ Exportações } \\
Mundo (US\$ bilhões) & 111,1 & 113,6 & 119,3 & 112,5 & 113,0 & 126,1 \\
Brasil exp. (US\$ milhões) & 999 & 1007 & 1022 & 892 & 822 & 900 \\
Brasil imp. (US\$ milhões) & 1.362 & 1.110 & 1.201 & 1.065 & 898 & 1.112 \\
& & & Percentagem & & \\
Mundo & 100 & 100 & 100 & 100 & 100 & 100 \\
Economias desenvolvidas & 37 & 37 & 37 & 38 & 38 & 36 \\
Europa Ocidental & 22 & 22 & 21 & 22 & 21 & 19 \\
América do Norte & 8 & 9 & 9 & 10 & 10 & 10 \\
Outros desenvolvidos & 7 & 7 & 6 & 6 & 7 & 6 \\
Econ. em desenvolvimento & 60 & 59 & 60 & 58 & 58 & 60
\end{tabular}




\begin{tabular}{|lcccccc|} 
Ásia & 51 & 50 & 51 & 48 & 49 & 51 \\
América Latina & 3 & 3 & 4 & 4 & 4 & 4 \\
Brasil & 0,90 & 0,89 & 0,86 & 0,79 & 0,73 & 0,71 \\
Europa Ocidental & 3 & 3 & 3 & 4 & 4 & 3 \\
África e Oriente Médio & 3 & 2 & 2 & 3 & 2 & 2 \\
Economias em transição & 3 & 4 & 4 & 4 & 4 & 4 \\
& & & Importações & & \\
Mundo & 100 & 100 & 100 & 100 & 100 & 100 \\
Economias desenvolvidas & 37 & 36 & 37 & 39 & 38 & 37 \\
América do Norte & 12 & 12 & 14 & 15 & 16 & 16 \\
Europa Ocidental & 17 & 16 & 16 & 17 & 16 & 14 \\
Outros países desenv. & 8 & 8 & 7 & 6 & 6 & 6 \\
Econ. em desenvolvimento & 56 & 55 & 55 & 51 & 53 & 55 \\
Ásia & 37 & 36 & 34 & 29 & 31 & 33 \\
África e Oriente Médio & 10 & 10 & 10 & 11 & 10 & 10 \\
América Latina & 6 & 6 & 7 & 8 & 8 & 9 \\
Brasil & 1,23 & 0,98 & 1,01 & 0,95 & 0,79 & 0,88 \\
Europa Ocidental & 3 & 3 & 3 & 3 & 3 & 3 \\
Economias em transição & 7 & 8 & 8 & 9 & 8 & 8 \\
\hline Fonte: Prochnik (2002), com base em dados da Secretaria da OMC. & & & \\
Nota: Os dados acima excluem o comércio de têxteis na União Européia (15) e as reexportações de Hong \\
Kong.
\end{tabular}

Tabela 2

Distribuição do comércio mundial de confecções, 1995-2000

\begin{tabular}{lccccccc}
\hline & 1995 & 1996 & 1997 & 1998 & 1999 & 2000 \\
\hline Mundo (US\$ bilhões) & 124,0 & 128,7 & 141,9 & 149,3 & 150,0 & 165,5 \\
Brasil exp. (US\$ milhões) & 298 & 248 & 211 & 185 & 173 & 282 \\
Brasil imp. (US\$ milhões) & 372 & 371 & 451 & 369 & 206 & 185 \\
& & & Percentagem & & \\
Mundo & 100 & 100 & 100 & 100 & 100 & 100 \\
Economias desenvolvidas & 19 & 21 & 20 & 19 & 18 & 17 \\
Europa Ocidental & 12 & 13 & 12 & 11 & 10 & 9
\end{tabular}

RAP Rio de Janeiro 40(1):57-80, Jan./Fev. 2006 
Articulação de Políticas Públicas a Partir dos Fóruns de Competitividade Setoriais 71

\begin{tabular}{lcccccc} 
América do Norte & 6 & 7 & 7 & 7 & 7 & 6 \\
Outros desenvolvidos & 1 & 1 & 1 & 1 & 1 & 1 \\
Econ. em desenvolvimento & 75 & 73 & 75 & 75 & 76 & 78 \\
Ásia & 56 & 54 & 54 & 52 & 52 & 54 \\
América Latina & 7 & 8 & 9 & 11 & 12 & 14 \\
Brasil & 0,24 & 0,19 & 0,15 & 0,12 & 0,12 & 0,17 \\
Outras econ. em desenv. & 6 & 6 & 5 & 6 & 6 & 6 \\
África e Oriente Médio & 6 & 6 & 6 & 6 & 5 & 5 \\
Economias em transição & 6 & 6 & 6 & 6 & 6 & 6 \\
& & & Importações & & \\
Mundo & 100 & 100 & 100 & 100 & 100 & 100 \\
Economias desenvolvidas & 80 & 80 & 77 & 79 & 80 & 80 \\
América do Norte & 32 & 32 & 34 & 37 & 38 & 41 \\
Europa Ocidental & 33 & 33 & 30 & 31 & 30 & 28 \\
Outros países desenvolvidos & 15 & 15 & 13 & 11 & 11 & 12 \\
Econ. em desenvolvimento & 15 & 15 & 16 & 16 & 16 & 15 \\
América Latina & 5 & 5 & 6 & 6 & 6 & 6 \\
Brasil & 0,30 & 0,29 & 0,32 & 0,25 & 0,14 & 0,11 \\
Ásia & 6 & 5 & 6 & 5 & 5 & 5 \\
Outras econ. em desenv. & 5 & 4 & 4 & 5 & 4 & 4 \\
Economias em transição & 4 & 4 & 5 & 5 & 4 & 4 \\
\hline Fonte: Prochnik (2002), com base em dados da Secretaria da OMC. & & & \\
Nota: Os dados acima excluem o comércio de têxteis na União Européia (15) e as reexportações de Hong \\
Kong. & & & & & & \\
\hline
\end{tabular}

Para discutir alternativas para esse quadro, articulando diversos atores para a consecução de políticas de desenvolvimento industrial para a cadeia produtiva, o Fórum de Competitividade da Cadeia Produtiva Têxtil e de Confecções foi constituído em 30 de maio de 2000. São membros integrantes do fórum:

setor produtivo - Associação Brasileira da Indústria Têxtil e de Confecção (Abit), Associação Brasileira dos Produtores de Algodão (Abrapa), Associação Brasileira do Algodão (Abralg), Associação Brasileira do Vestuário (Abravest), Associação Brasileira de Produtores de Fibras Artificiais e Sintéticas (Abrafas), Central Única dos Trabalhadores (CUT), Confederação Geral dos Trabalhadores (CGT), Força Sindical, Social Democracia Sindical (SDS), Serviço Nacional da Indústria (Senai) e Serviço Brasileiro de Apoio às Micro e Pequenas Empresas (Sebrae); 
t setor público - ministérios do Desenvolvimento, Indústria e Comércio Exterior (MDIC), da Ciência e Tecnologia (MCT), da Agricultura, Pecuária e Abastecimento (Mapa), da Fazenda (MF), da Integração Nacional (MIN), do Trabalho e Emprego (MTE), e as instituições financeiras oficiais federais: Banco Nacional do Desenvolvimento Econômico e Social (BNDES), Banco do Brasil (BB), Caixa Econômica Federal (Caixa), Banco do Nordeste (BN) e Banco da Amazônia (Basa).

A discussão sobre quais políticas de desenvolvimento adotar se deu com base em um diagnóstico feito pela área setorial têxtil do BNDES, sobre o qual houve amplo consenso por parte dos membros. Com base nesse estudo, foram definidos os seguintes princípios básicos e metas, consubstanciados no Contrato de Competitividade. $^{2}$

\section{Macrometas $^{3}$}

t Aumentar o número de postos de trabalho em 160 mil na indústria e 160 mil na agricultura no período de 1999 a 2011.

t Aumentar as exportações para US\$ 4,3 bilhões em 2008, o que significa atingir $1,0 \%$ das exportações mundiais de têxteis.

Ações por metas instrumentais e políticas prioritárias

Com impactos na competitividade do conjunto da cadeia produtiva:

t ampliar a área plantada de algodão dos atuais 600 mil ha para 1.200 mil ha no período de 1999 a 2005, usando técnicas que não degradem o meio ambiente. Essa expansão ocorrerá, fundamentalmente, em área de cerrado de diversos estados brasileiros;

\footnotetext{
${ }^{2}$ Contrato de Competitividade é uma declaração de intenções, em que definem-se os compromissos do governo federal e do setor produtivo (empresários e trabalhadores), considerando os propósitos maiores do desenvolvimento do país expressos na geração de emprego e renda, melhoria da balança comercial, desenvolvimento produtivo regional e progresso tecnológico.

${ }^{3}$ Todas as metas foram revistas, em setembro de 2002, devido à recessão dos principais mercados têxteis no mundo.
} 
t realizar investimentos em modernização e expansão da capacidade produtiva em todos os elos da cadeia, em um horizonte de 11 anos, no valor total de US\$ 12,6 bilhões;

t aumentar a produtividade de mão-de-obra em cerca de 30\% nos segmentos têxtil, fibras e confecções no período de 1999 a 2008;

t aprimoramento dos procedimentos de controle e de fiscalização das importações de itens referentes à cadeia produtiva nos portos brasileiros;

t desoneração da produção.

Com impactos em segmentos específicos da cadeia:

t aumento da competitividade do segmento de fibras químicas;

t aprimoramento dos critérios de classificação do algodão;

t melhoria do sistema de comercialização e seguro agrícolas;

t prospectiva tecnológica nos segmentos de algodão, têxtil e confecções;

t regionalização da produção.

Nestes três anos desde sua instalação, muitas ações têm sido articuladas com vistas a incrementar a competitividade da cadeia e, de forma geral, as metas têm sido cumpridas. Quanto à balança comercial, por exemplo, a cadeia conseguiu reverter a tendência negativa de meados da década de 1990, fechando o ano de 2001 com o primeiro saldo positivo desde 1994, no valor de US\$ 73 milhões ${ }^{4}$ e atingindo, em 2003, saldo de US\$ 594 milhões. Esta nova situação, sustentável, fundamentou-se na solução da produção interna de algodão e no processo de modernização alcançado na área de confeccionados, que incorporou tecnologia e capacidade de agregar valor a seus produtos, além de melhorar e ampliar sua capacidade de produção, vindo a se inserir em novos mercados consumidores e competir com a importação de produtos confeccionados, especialmente os provenientes da Ásia.

Quanto à geração de empregos, também houve uma reversão do quadro de desemprego decorrente do ajuste da década de 1990. Segundo dados do Ministério do Trabalho e Emprego, a cadeia gerou, em 1999 e 2000, 96.240 novos empregos. Ressalte-se, ainda, que apesar dos anos de 2001, 2002 e 2003 terem sido

\footnotetext{
${ }^{4}$ Dados do Sistema Aliceweb, do Ministério do Desenvolvimento, Indústria e Comércio Exterior.
} 
particularmente complexos, devido ao racionamento de energia elétrica, à recessão interna e ao desaquecimento do mercado mundial de têxteis, a cadeia ainda gerou, de janeiro de 2001 a agosto de 2003, 36.694 novos empregos formais.

No fórum, os elos que mais se destacaram foram os de algodão e de confecções. O primeiro, fundamentalmente, por ter sido o único a entender o fórum como um campo estratégico, incorporando os stakeholders ao processo de formulação e implementação de políticas. Como descrito pela literatura contemporânea, os mecanismos de ownership da política por setores estratégicos são vitais, pois são estes atores que dão sustentação à política e legitimidade ao desenho estratégico das políticas (Silva e Melo, 2000). Para o elo de confecções, houve esforço concentrado por parte dos atores por ser o foco principal das ações na cadeia - por se tratar do elo mais frágil e que mais agrega valor.

Entre as políticas desenvolvidas para apoiar a competitividade do elo de algodão pode-se citar (Brasil, 2002):

t pesquisas e transferência de tecnologias realizadas pela Embrapa voltadas ao aperfeiçoamento dos sistemas de produção e ao desenvolvimento de novas variedades de algodão;

t linhas de crédito formatadas para atender às especificidades do elo;

t criação de nova modalidade de adiantamento de contrato de câmbio (ACC) para pessoa física, que beneficiou produtores de algodão;

t redução no imposto para importação de máquinas e equipamentos utilizados sem produção nacional;

t adequação da classificação do algodão segundo os parâmetros mundiais;

t apoio à melhoria do sistema de comercialização, por meio da realização de leilões de contrato de opção de venda, prêmio para escoamento do produto (PEP) e exercício de opção (aquisição do produto pelo governo);

t estabelecimento de um painel (Comitê de Arbitragem) na Organização Mundial do Comércio contra os subsídios pagos pelo governo norte-americano aos cotonicultores;

t autorização de operações de drawback para importações de matérias-primas e outros insumos utilizados no cultivo de produtos agrícolas a serem exportados;

t incentivo à criação do sistema Abrapa de identificação por código de barras, que dá rastreabilidade ao fardo de algodão. 
Quanto à competitividade do elo de confecções, a principal política desenvolvida diz respeito à utilização de mecanismos de apoio aos arranjos produtivos locais (APL), com foco na competitividade das micro, pequenas e médias empresas. Para tanto foi estabelecida parceria entre MDIC, BNDES, Banco do Brasil, Caixa Econômica Federal, Banco do Nordeste, Sebrae, Senai, Abit e sindicatos das empresas locais e entidades empresariais para desenvolvimento de ações nas áreas de: capacitação gerencial e de recursos humanos, crédito, apoio tecnológico, qualidade e produtividade, e design voltados ao segmento de confecções.

Esta intervenção é fruto de uma nova percepção de políticas públicas de desenvolvimento, em que o local passa a ser visto como um eixo orientador de promoção econômica e social. De fato, diversos teóricos têm enfatizado que o desenvolvimento está enraizado nas condições locais e que a economia global reforça a importância dos tecidos locais, gerando uma dinâmica regional diferenciada, com segmentações territoriais e sociais (Diniz, 2001).

Assim, a idéia de aglomerações torna-se associada ao conceito de competitividade e, portanto, objeto de intervenção de políticas públicas. Por entender dessa maneira, o Plano Plurianual 2004-07 contemplará um amplo programa, de caráter interinstitucional, contendo ações integradas de apoio aos APLs. Além disso, a nova política industrial tem nos APLs um importante instrumento de rebatimento regional da política de desenvolvimento para o país.

Reforçando a importância da formação de redes, o MDIC tem buscado coordenar esforços que potencializem a atuação do conjunto dos atores envolvidos, buscando induzir ao desenvolvimento mediante um esforço articulado, com foco na geração de emprego e renda e no aumento da competitividade. Assim, cabe ao Fórum de Competitividade setorial articular a política específica em nível nacional para facilitar o envolvimento dos atores locais, principalmente em relação àquelas instituições com elevado grau de capilaridade como: Sebrae, Senai e bancos oficiais.

Pelo exposto, torna-se claro que embora o Fórum de Competitividade da Cadeia Produtiva Têxtil e de Confecções ainda se configure em uma rede de políticas em que os conflitos sejam bastante presentes, a interação dos atores envolvidos está mais freqüente se comparada à época de sua instalação. Não obstante, conforme frisado por Silva e Melo (2000), “o contexto institucional e organizacional brasileiro caracteriza-se por especificidades importantes — entre as quais destaca-se sua complexidade e forte diferenciação funcional e principalmente os problemas de coordenação e cooperação intergovernamentais”.

De fato, o fórum não parece ter ainda totalmente equacionado uma variável crucial para sua boa operacionalização: a forma de implementação do programa.

Na literatura, muita ênfase tem sido dada à implementação como variável fundamental para o sucesso de políticas públicas. Silva e Melo, por exemplo, chegam a considerá-la “o ‘elo perdido’ nas discussões sobre a eficiência e eficácia da ação 
governamental”. Modelo alternativo para a formulação de uma política, o teste ACIDD, ${ }^{5}$ por sua vez, considera a implementação no contexto dos interesses e na aceitação dos atores envolvidos, em que devem ser equacionadas as questões relacionadas à seleção de instrumentos de políticas e métodos de execução (tradicionalmente, muitas dessas questões são operacionais e só consideradas após uma decisão em relação a uma política já ter sido tomada, Taylor, s.d.).

Neste caso em análise, as dificuldades de implementação estiveram associadas a problemas variados:

t forte resistência ao programa por parte de alguns dos órgãos de governo vitais para o desenvolvimento de políticas setoriais;

t ausência de mecanismos claros de encaminhamento das propostas oriundas das discussões do fórum;

t não há instância superior (interministerial) que delibere sobre ações/medidas que não são consenso entre os atores;

t dificuldade de convencer o setor produtivo a encaminhar soluções para a cadeia produtiva utilizando a concepção tripartite;

t embora a metodologia do programa entenda a formulação e implementação de políticas como um processo, não é rara a visão hierárquica da burocracia pública como correspondente ao ideal weberiano, que pressupõe o funcionamento da administração pública como um mecanismo operativo perfeito, consagrando uma visão top-down da formulação e desenho de programas;

t falta de um sistema de informação/interação permanente entre os atores, criando uma responsabilidade compartilhada da coordenação das ações (aliviando a sobrecarga do coordenador técnico do fórum).

É oportuno, por fim, lembrar que as novas diretrizes de política industrial, tecnológica e de comércio exterior tendem a fortalecer o Fórum de Competitividade, por utilizá-lo como ferramenta de formulação e desenho de políticas setoriais, o que pode quebrar a resistência de alguns órgãos a participar efetivamente deste diálogo. Cabe, no entanto, aos atores integrantes aproveitarem a retomada da discussão em torno da

\footnotetext{
${ }^{5} \mathrm{O}$ teste ACIDD é uma estrutura para o planejamento de políticas que incorpora os ingredientes e processos envolvidos na formulação de uma política como elementos de um sistema integrado que é definido iterativa e simultaneamente. ACIDD é uma sigla em inglês dos seguintes componentes: análise, escolha, implementação, debate e decisão.
} 
política industrial para articularem medidas e instrumentos dentro das quatro linhas de ação horizontais consideradas pelo governo federal na implementação da política industrial, tecnológica e de comércio exterior: inovação e desenvolvimento tecnológico; inserção externa; modernização industrial; e capacidade e escala produtiva (Presidência da República, 2003).

\section{Conclusões}

Ao analisar a evolução do padrão de desenvolvimento recente da CTC durante a década de 1990, constata-se que a abertura comercial dissociada de sólidas políticas de competitividade forçou a reestruturação de todos os elos da cadeia para fazerem face ao desafio da concorrência internacional.

Ainda que o fortalecimento dos elos tenha sido vital para a sobrevivência da cadeia produtiva, não é condição suficiente para uma inserção dinâmica e significativa no mercado internacional a longo prazo. Isso demanda redes sólidas de políticas específicas de desenvolvimento produtivo, tecnológico e de comércio internacional. Assim, o Fórum de Competitividade da cadeia têxtil e de confecções foi instalado em 2000, para discutir o diagnóstico e um conjunto de ações e metas desafiadoras para a solução dos problemas e aproveitamento das oportunidades.

Como citado, nesses quase quatro anos muito se avançou no que tange às alianças firmadas entre os atores dessa comunidade política. Saliente-se, no entanto, que o algodão tem sido o único elo a efetivamente utilizar o fórum como um campo estratégico, incorporando os stakeholders ao processo de formulação e implementação de políticas.

Muito embora o algodão seja um elo estratégico para a cadeia, a ausência de mecanismos de ownership da política pelos demais elos tem gerado sinergia insuficiente para discutir soluções para elos em que as economias de escala empresariais são imprescindíveis.

O elo de fibras manufaturadas, por exemplo, não foi capaz de gerar resultados competitivos em termos de comércio exterior, justamente pela posição pouco importante das filiais brasileiras nas redes de fornecimento intra-empresas das grandes corporações. No Brasil, a tendência mundial de aumento de utilização de fibras químicas em relação às naturais não tem se observado, embora possua, claramente, maior competitividade relativa. Nesse sentido, são necessárias políticas governamentais de atração de investimentos articuladas com políticas setoriais industriais de tecnologia e comércio exterior.

Embora não tratado neste artigo, o elo de bens de capital tem observado um aumento considerável nas importações de máquinas e equipamentos têxteis, ${ }^{6}$ e nem sequer é tratado separadamente em um grupo temático específico do Fórum de Com- 
petitividade. Os elos de fiação, tecelagem e malharia, por sua vez, necessitam aprofundar a discussão sobre consolidação de grandes grupos nacionais, para que um patamar mínimo de escala empresarial seja alcançado. Além disso, é preciso um forte trabalho de design para os elos de tecelagem e malharia.

No que diz respeito a ações para geração de emprego e renda é preciso que se compreenda que criar empregos exige ação mais efetiva. No caso da cadeia em estudo, o elo de confecções possui o menor gasto de capital por posto de trabalho, o que o torna um dos grandes empregadores em qualquer parque industrial do mundo.

Portanto, gerar empregos na cadeia têxtil significaria dar maior competitividade ao segmento de confecções, buscando desde macropolíticas de incentivo ao empreendedorismo, de diminuição da informalidade e de uma reforma nas leis trabalhistas, até políticas que visem a maior organização da produção das pequenas empresas, via apoio a APLs ou cooperativas, maior treinamento de mão-de-obra envolvida na produção, em nível operacional, gerencial ou de controle, e maior grau de utilização de equipamentos $\mathrm{CAD} / \mathrm{CAM}^{7}{ }^{7}$ entre outras medidas igualmente importantes, tais como a solução da questão do financiamento para a modernização tecnológica das pequenas empresas.

Caberia ao fórum articular uma política nacional que envolvesse os atores locais nos arranjos produtivos locais (APLs) de confecções, em consonância com o Grupo de Trabalho Interministerial, criado em dezembro de 2003, que buscará articular os esforços para mostrar caminhos de ações coletivas para o desenvolvimento dos APLs de diversas cadeias produtivas. Cabe frisar que embora haja ações por parte dos diversos atores, não se pode afirmar que as parcerias têm sido constantes. De fato, ainda são poucas as ações coletivas empreendidas até o momento.

Resgate-se, por fim, a idéia de que as novas diretrizes de política industrial, tecnológica e de comércio exterior tendem a fortalecer o Fórum de Competitividade, por utilizá-lo como ferramenta de formulação e desenho de políticas setoriais. No caso específico do setorial têxtil, as novas diretrizes ainda diminuem algumas dificuldades de implementação como a resistência de alguns órgãos e a criação de instâncias de coordenação e operação das políticas como o Conselho de Desenvolvimento Econômico e Social (CDES) e a Câmara de Política Econômica/ PR.

Não obstante, para que o Fórum de Competitividade da Cadeia Têxtil e de Confecções se fortaleça é necessário um forte apoio político, aliado a um sistema de

\footnotetext{
${ }^{6}$ Do consumo aparente do setor têxtil em 1998, verifica-se que 32\% da maquinaria foram produzidos nacionalmente, enquanto 68\% foram importados (Cetiqt, 2003).

${ }^{7} \mathrm{CAD}$ - computer aided design; CAM — computer aided manufacturing.
} 
informação/interação permanente entre os atores e à criação de mecanismos claros de encaminhamento das propostas oriundas das discussões do fórum.

\section{Referências bibliográficas}

BRASIL. MDIC (MINISTÉRIO DO DESENVOLVIMENTO, INDÚSTRIA E COMÉRCIO EXTERIOR). Documento básico dos fóruns. Brasília: Secretaria do Desenvolvimento da Produção, 2000.

MDIC. Relatório de resultados: cadeia produtiva têxtil e de confecções. Brasília: Secretaria do Desenvolvimento da Produção, 2002.

Presidência da República. Diretrizes de Política Industrial, Tecnológica e de Comércio Exterior. Brasília: Casa Civil, 2003.

CETIQT (CENTRO DE TECNOLOGIA DA INDÚSTRIA QUÍMICA E TÊXTIL). Avaliação estrutural da cadeia produtiva têxtil e de vestuário. Rio de Janeiro: Instituto de Prospecção Tecnológica e Mercadológica, 2003.

COUTINHO, L.; HIRATUKA, C.; SABBATINI, R. O desafio da construção de uma inserção externa dinamizadora. Rio de Janeiro: UFRJ, 2003.

DINIZ, C. Globalização, escalas territoriais e política tecnológica regionalizada no Brasil. Belo Horizonte: UFMG/Caedeplar, 2001. (Texto para discussão n. 168).

FUNDAÇÃO VANZOLINI. A competitividade das cadeias produtivas da indústria têxtil baseadas em fibras químicas: relatório final do estudo. São Paulo: Fundação Vanzolini, 2001.

IEL (INSTITUTO EUVALDO LODI). Análise da eficiência econômica e da competitividade da cadeia têxtil brasileira. Brasília: Núcleo Central, 2000.

2003.

. Diagnóstico da indústria do vestuário de São João Nepomuceno. Belo Horizonte: IEL,

IEMI (INSTITUTO DE ESTUDOS E MARKETING INDUSTRIAL). Relatório setorial da indústria têxtil brasileira. São Paulo: Parma, 2002.

PROCHNIK, V. Cadeia: têxtil e confecções. Campinas: Unicamp-IE-NEIT, 2002.

SILVA, P.; MELO, M. O processo de implementação de políticas públicas no Brasil: características e determinantes da avaliação de programas e projetos. São Paulo: Nepp, 2000. (Caderno n. 48).

TAYLOR, C. O teste ACIDD: uma estrutura para o planejamento de políticas e processos decisórios. Optimum. The Journal of Public Sector Management, v. 27, n. 4, p. 53-62, s.d.

ZURBRIGGEN, C. Las redes de políticas públicas: una revisión teórica. Espanha: Universitat Oberta de Catalunya, 2003. 